E. E. CLAYTON und T. E. SMITH, Resistance of tobacco to bacterial wilt (Bacterium solanacearum). (Resistenz des Tabaks gegen Bakterienwelke [Bacterium solanacearum].) Journ. agric. res. $65,547-554$ (I942).

Die wirtschaftliche Bedeutung dieser seit 60 Jahren bekannten Krankheit geht daraus hervor, daß in Befallsgebieten verseuchte Ackerflächen nur ein Viertel ihres sonstigen Wertes besitzen. Schon r9o3 strebte man die Züchtung resistenter Tabaksorten an, ohne jedoch zunächst Erfolg zu haben. Ein Menschenalter später nahm. man die Arbeiten auf breiter Grundlage wieder auf. Keine der wilden Nicotiana-Arten besitzt Resistenzeigenschaften. Von mehr als I ooo mexikanischen, mittel- und südamerikanischen Nicotiana tabacum-Herkünften zeigten einige wenige Resistenz. Durch Kreuzung von T. I. 79 A and Turkish Xanthi, zwei mäBig resistenten Stämmen, wurde eine hochresistente Form ( $79-\mathrm{X})$ gezüchtet, die aber qualitativ geringwertig war. Hohe Welkeresistenz, verbunden mit guter Qualität, besitzt eine aus Kolumbien stammende Form (T.I. $448 \mathrm{~A}$ ). Diese auch gegen das Tabakmosaikvirus hoch resistente Form zeigte im Verlauf dreier Jahre stets weniger als Io\% Verlust, während anfällige Formen hundertprozentig vernichtet wurden. M. Klinkowski (Aschersleben).

W. J. ZAUMEYER und L. L. HARTER, Inheritance of resistance to six physiologic races of bean rust. (Vererbung der Resistenz gegen 6 physiologische Bohnenrostrassen). Journ. agric. res. $63,599-622$ (194I).

Es ist bekannt, daß die Resistenz gegen den Weizenschwarzrost nicht bei allen Sorten and bei den verschiedenen Rassen in gleicher Weise vererbt wird. Die vorliegende Untersuchung befaßt sich mit der Frage der Vererbung der Resistenz bei einer Reihe von Bohnenhybriden gegen 6 physiologische Rassen des Bohnenrostes. Geprüft wurden die Rassen $I, 2,6$, rI, I2 und $I 7$. Bei den Rassen $I$ und 2 beruht die Resistenz auf einem Mendelfaktor, bei den anderen Rassen sind wahrscheinlich noch andere genetische Faktoren an der Resistenz beteiligt. Die Resistenz war dominant bei den Rassen I, 2, 6 und I2, nur unvollkommen bei den Rassen I und I 7 . Stark gescheckte Pflanzen waren immun gegen Rasse 6 , schwach gescheckte weniger anfällig als normale. Dies kann in dem physiologischen Verhalten des Wirtes oder des Erregers begründet sein oder auf modifizierende genetische Faktoren zurückzuführen sein oder auf einer Kombination aller genannten Ursachen beruhen. Es ist möglich, daß ein Gen die Resistenz bedingt und ein anderes Gen die Anfälligkeit. Daneben können modifizierende Faktoren für variable Resisten $z$ - und Anfälligkeitsgrade innerhalb der größeren Klassen verantwortlich sein. Eine mit Rasse II geimpfte $F_{\text {, }}$ zeigte verschiedene, vorher nicht beobacbtete Resistenz- und Anfälligkeitsklassen, was teilweise die Erklärung für das Vorhandensein dieser variablen Klassen in der $F_{3}$ gibt. Transgressive Spaltung wurde bei mit Rasse I g geimpften Bastarden beobachtet, wobei ein Viertel der $F_{8}$ eine höhere Resisten $z$ als der weniger anfällige Elter zeigte. In der $F_{2}$, geimpft mit Rasse I7, zeigte sich, daß die Umwelt einen Einfluß auf den Infektionsgrad der intermediären Klasse besitzt. Unter ungünstigen Verhältnissen erschienen die Pflanzen resistent und spalteten im Verhältnis 3 resistent : I anfällig. Unter günstigeren Verhältnissen lautete das Spaltungsverhälnis $\mathrm{I}: 2: \mathrm{I}, \quad M$. Klinkowski (Aschersieben).
R. D. BROCK, The nature of fusarium wilt resistance in the tomato variety Pan America. (Die Art der Fusariumwelkeresistenz bei der Tomatensorte Pan Amerika.) Journ. austral, inst. of agric. sci. I4, $78-80$ (i948).

Die gegen Fusarium bulbigenum var. lycopersici resistente Tomatensorte Pan Amerika ist in den Vereinigten Staaten von PORTE und WALKER gezüchtet worden. Sie erwies sich auch in Australien feldresistent. Über die Art der Resistenz wurden bisher verschiedene Auffassungen geäußert. Bei Infektion entstehen bei den nicht welkenden Pflanzen einige Gefäßverbräunungen in der Wurzel. Die Reisolierung des Krankheitserregers gelingt aus gesund erscheinenden und verbräunten Wurzeln. Die Gefäßverbräunungen reichen nicht bis in die oberirdischen Organe; dort bleiben daher Isolierungsversuche erfolglos. Der Krankheitserreger kann also in die Wurzel eindringen, jedoch ist sein Wachstum dort und seine Befähigung zur Welkeerzeugung gehemmt. Chloroformhaltige Luft $(0.02$ $\mathrm{ccm} / 1)$ vermochte nach erfolgter Infektion die Krankheitsrate, im Gegensatz zu Getreiderosten, nicht zu erhöhen. Zusätzliche Infektionen vorher infizierter Pflanzen mit dem Virus der Bronzefleckenkrankheit der Tomate und Kartoffel X-Virus ergaben im ersteren Falle eine deutliche Steigerung der Anfälligkeit. Es wird angenommen, daß die Resistenz der Sorte Pan America auf der Wachstumshemmung des Krankheitserregers beruht, wobei sich ein gewisses Gleichgewicht einstellt. Die Resistenz beruht also nicht auf der Unmöglicbkeit des Eintrittes des Krankheitserregers oder seiner Lokalisierung in der Wurzel. Tritt, wie im Falle der Bronzefleckenkrankheit, ein stark virnlentes Virus hinzu, dann wird dieses Gleichgewicht außer Kraft gesetzt und die Resistenz so herabgesetzt, daß der Pilz jetzt auch in die oberirdischen Teile der Pflanze eindringen kann. Ist das Virus weniger virulent, wie dies bei Kartoffel $\mathrm{X}$-Virus zutrifft, so ist die Wirkung entsprechend schwächer. M. Klinkowski (Aschersleben).

J. E. LIVINGSTON, The inheritance of resistance to Ustilago nuda. (Die Vererbung der Resistenz gegen Ustilago nuda.) Phytopathology 32, 45I-466 (I942).

Die Schwierigkeit bzw. technische Umständlichkeit der Bekämpfung des Gerstenflugbrandes durch die Heißwasserbeize führte dazu, sich mit der Frage der Resistenz und ihrer Vererbung näher $z u$ befassen. Dem Studium dienten Bastarde zwischen den anfälligen Sorten Missouri Early Beardless und Colsess IV und der resistenten Sorte Trebi und Hordeum deficiens. Infektionsversuche mit $\mathrm{F}_{1}$-Pflanzen aus Kreuzungen von Trebi mit Colsess IV ließen erkennen, daß die Infektionstypen der Chlamydosporen die Embryonen zu gleichen Anteilen erreichten, also unabhängig von Resistenz oder Anfälligkeit des weiblichen Elter. Die Sorte Trebi oder Hordeum deficiens besitzen einen dominaten Resistenzfaktor. Die Dominanz ist jedoch nicht immer vollständig. F -Nachkommenschaften beider Formen mit Missouri Early Beardless zeigten, daß die Resistenzfaktoren beider Eltern ähnlich sind. In der $F$, und den nachfolgenden Generationen herrschten resistente Pflanzen vor. Eine Kopplung zwischen den Resistenzfaktoren und denen für Sechszeiligkeit besteht nicht. Im Verlauf dieser Untersucbungen erhielt man vielversprechende sechszeilige, flugbrandresistente Wintergersten.

\section{Klinkowski (Aschersleben).}

\section{Personelle Mitteilung.}

Die Rabbethge u. Giesecke Saatzucht GmbH, Einbeck (Hannover), hat nach dem plötzlichen Tode ihres langjährigen Saatzuchtleiters Dr. phil. Friedrich SchneIDER dessen bisherigen Mitarbeiter, Dr. phil. habil. EDGAR KNAPP, frïher o. Professor für Genetik an der Reichsuniversität Straßburg and Dr. phil. habil. LunwIGARnold Schlösser, früher Dozent für Genetik und Züchtungsforschung an der Universität Göttingen und langjähriger Direktor des Forschungsinstitutes Kleinwanzleben der Rabbethge u. Giesecke A. G. mit der Weiterführung der züchterischen Arbeiten an Zuckerund Futterrüben betraut.

\section{Berichtigung}

zum Beitrag A. ScAMoNi, Die weitere Entwicklung der Kreuzungen zwischen Lavix europaea DC. und Larix leptolepis Murray in Eberswalde"1.

Die Tabelle ,,Prozentuale Verteilung auf den einzelnen Höhenstufen in Prozenten" auf Seite I93 muß richtig wie folgt lauten:

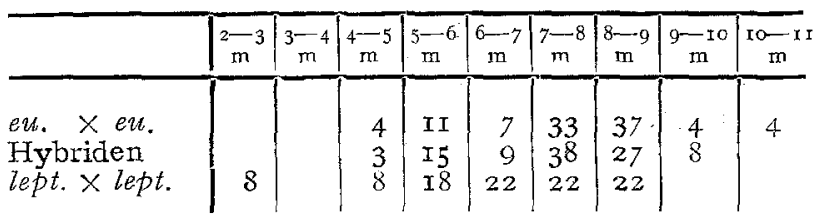

1 Der Züchter I9, I92-r96 (I949). 